\title{
ICDP Workshop on Borehole Monitoring at the Nankai Subduction Zone: Building a Land-Ocean Borehole Network to Study the Seismogenic Zone
}

by Takeshi Sagiya

doi:10.2204/iodp.sd.6.13.2008

Examples of subduction processes are currently investigated around the Kii Peninsula, Honshu Island by Japanese as well as international projects. The most well-known is the NanTroSEIZE project conducted by the Integrated Ocean Drilling Program (IODP). Drilling (riserless) with the drillship Chikyu started southeast off the Kii Peninsula in October 2007. In addition, the Japanese government launched a new project called Dense Ocean floor Network System for Earthquakes and Tsunamis (DONET) to install an integrated ocean bottom cable system for continuously monitoring earthquakes and tsunamis between the Kii Peninsula and the NanTroSEIZE drilling site. On land on the Kii Peninsula, an array of shallow boreholes for monitoring changes in groundwater level and strain is being constructed by Japan's National Institute of Advanced Industrial Science and Technology (AIST, Fig. 1). As part of the latter project, the International Continental Scientific Drilling Program (ICDP) organized and funded a workshop to prepare for land-based intermediate depth drilling to install monitoring equipment complementing the AIST and NantroSEIZE projects.

The "ICDP Workshop on Borehole Monitoring at the Nankai Subduction Zone: Building a Land-Ocean Borehole Network to Study the Seismogenic Zone" was conducted on 20-23 August 2007 at Nagoya University. Thirty-five scientists from four countries participated. Eighteen presentations addressed the seismic activity along the Nankai Trough

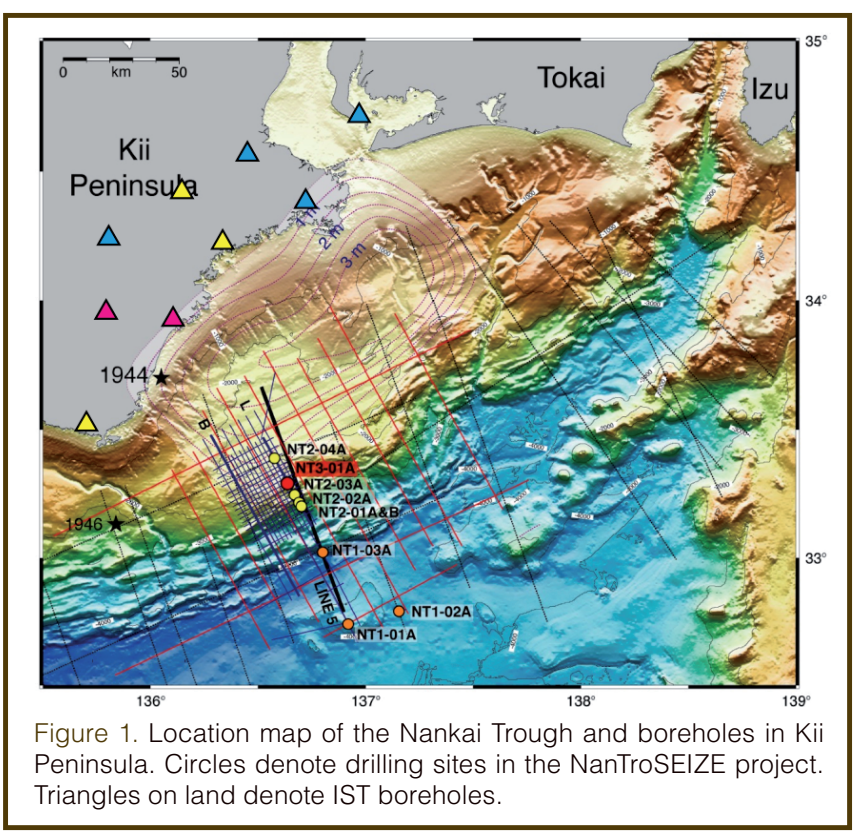

subduction zone, geologic background of the Kii Peninsula, present status of various ongoing projects (NanTroSEIZE, DONET, etc.), and state-of-the-art observatory technologies.

Other key topics included pore pressure measurements and technical aspects of the planned monitoring system and its installation. The discussion of the merits of pore pressure measurement led to the conclusion that such data must be one of the main parameters to be monitored in the Nankai Trough subduction complex. For strain measurements, two options were considered in detail. An integrated monitoring system of the Tono Research Institute of Earthquake Science in Mizunami, Japan, shows high sensitivity and good stability. Alternatively, optical fiber strain meters can be installed outside the borehole casing to allow using the boreholes for other purposes such as repeated downhole logs or permanent measurements inside casing. Another finding was that seismological monitoring and analysis should be included to study non-volcanic deep tremors.

A major part of the workshop was dedicated to preparation of a drilling proposal including discussion of prioritized scientific targets. Considering recent findings like non-volcanic deep low-frequency tremors (e.g. Obara, 2002), slow slip events (e.g. Ozawa et al., 2002), and ultra-slow earthquakes (e.g. Ito et al., 2007), participants agreed that the goal of drilling and monitoring is to resolve the complex behavior of the plate boundary megathrust at the deeper end of the locked zone.

A field trip was made to the Kii Peninsula to visit two geologic sites exhibiting Miocene igneous acidic rocks characterizing the southeastern part of the Kii Peninsula. The integrated borehole groundwater observatory constructed by AIST visited Kumano City (Fig. 2). The observatory was

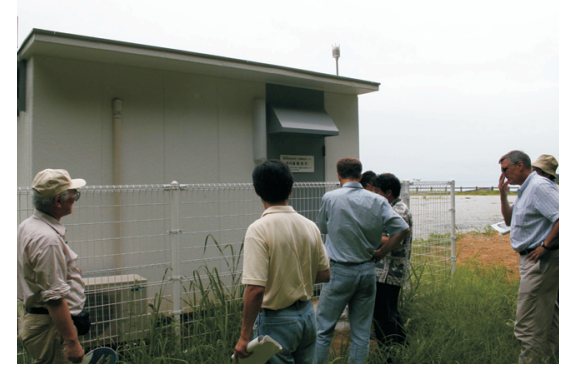

Figure 2. Field trip to the integrated borehole groundwater observatory of AIST. designed to detect precursory ground water level changes before a large megathrust earthquake (there were reports of ground water level change before the 1946 Nankai earthquake) and to investigate various 


\section{Workshop Reports}

plate boundary phenomena with precise observation with strainmeter, tiltmeter, and a seismograph. Finally, Kata village of Owase City, Japan was visited, where tsunami run-up heights were recorded and displayed on a telegraph pole (Fig. 3). The 1944 Tonankai and the 1854 Anse-Tokai earthquakes also shook this area. This display teaches us that the last earthquake in 1944 was a moderate one, and the region may have to prepare for a stronger one similar to the 1854 event.

The whole workshop was very successful in raising the understanding on various ongoing projects, introducing state-of-the-art monitoring techniques to potential project proponents as well as technical problems to be resolved. It also defined the goals and milestones towards a full drilling proposal planned for submission to ICDP by fall 2008 .

\section{Acknowledgements}

The author would like to express sincere thanks to ICDP and the Japan Drilling Earth Science Consortium (J-DESC) for their financial support of the workshop.

\section{References}

Ito, Y., Obara, K., Shiomi, K., Sekine, S., and Hirose, H., 2007. Slow earthquake coincident with episodic tremors and slow slip events. Science, 315:503-506, doi:10.1126/science.1134454.

Obara, K., 2002. Nonvolcanic deep tremor associated with subduction in southwest Japan. Science, 296:1679-1681, doi:10.1126/science.1070378.

Ozawa, S., Murakami, M., Kaidzu, M., Tada, T., Sagiya, T., Yarai, H., and Nishimura, T., 2002. Detection and monitoring of ongoing aseismic slip in the Tokai region, central Japan. Science, 298: 1009-1012, doi:10.1126/science.1076780.

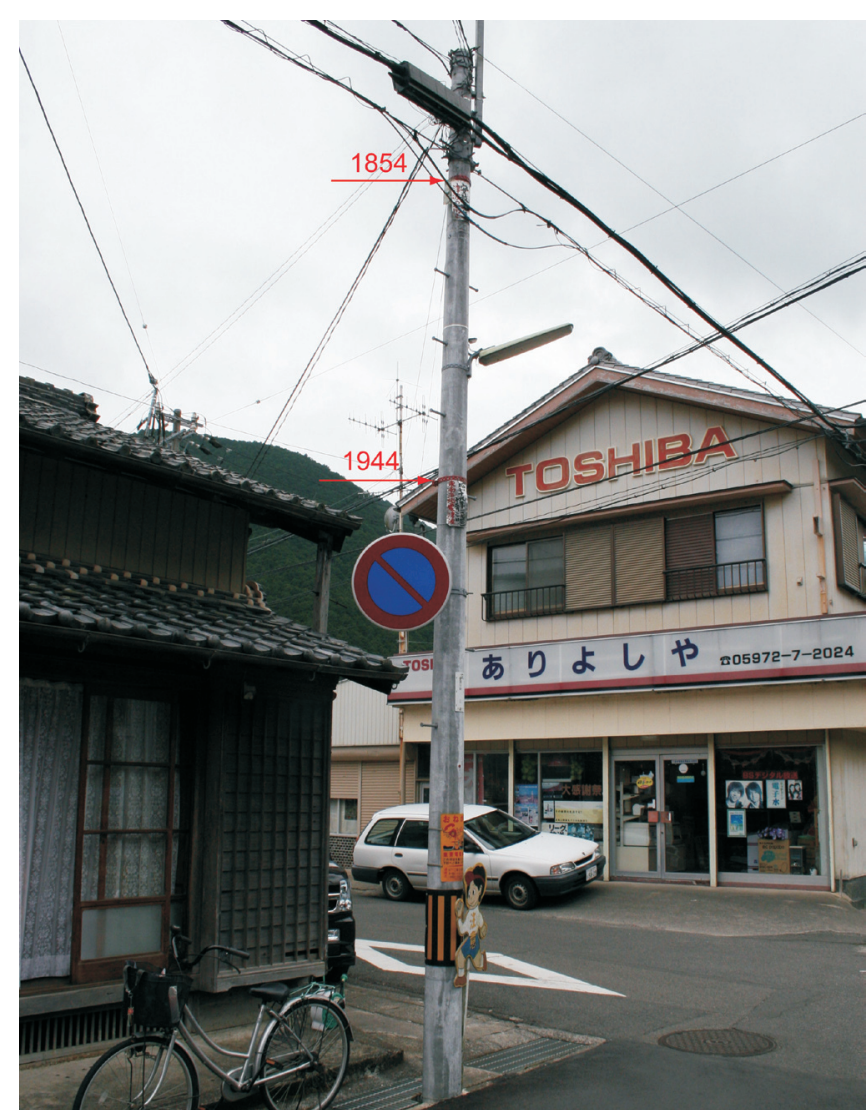

Figure 3. Display of tsunami heights (in red on pole) in Kata village, Owase City.

\section{Author}

Takeshi Sagiya, Research Center for Seismology, Volcanology, and Disaster Mitigation, Graduate School of Environmental Studies, Nagoya University, Furo-cho, Chikusa-ku, Nagoya 464-8601 Japan, e-mail: sagiya@seis. nagoya-u.ac.jp. 